\title{
Reflections and Experiences of Parents During Hospitalization of Children and Support Provided by the Staff at the Paediatric Hospital of Tirana
}

\author{
M.A. Matilda Memaj \\ University of Tirana, Faculty of Social Sciences, Department of Social Work and Social Policies \\ "Gjergj Fishta" Boulevard, Tirana, Albania; Email: mmemaj@yahoo.com \\ Dr. Irida Agolli (Nasufi) \\ University of Tirana, Faculty of Social Sciences, Department of Social Work and Social Policies \\ "Gjergj Fishta" Boulevard, Tirana, Albania; Email: iagolli@yahoo.com
}

Doi:10.5901/jesr.2015.v5n3p251

\begin{abstract}
Hospitalization of children can create difficult and emotional psycho-social situations for children and their families. Hospitalization may be strongly or naturally experienced by children depending on what is the level of their preliminary preparation to the hospitalization process. The study aims to address the parents' experiences during hospitalization of children and medical and psycho-social services offered for children and their parents/guardians. A combination of qualitative and quantitative methods was used for data collection. The study has included parents of hospitalised children and medical and psycho-social staff offering services for these children. Parents report that in general there is a lack of preparation procedures for the process of children hospitalization, while the staff is only focused on providing medical service. Most of the parents participating in this study have chosen not to inform their children about their disease and not to allow medical staff or even professionals of psycho-social service either to do such a thing. The psycho-social service is in its first steps and most of the parents are not aware of this service. Children and parents should be part of decisions related to the treatment and procedures the children will go through. The psycho-social service offers a greater support for the family, children and medical staff.
\end{abstract}

Keywords: child hospitalization, parent's experience, support

\section{Introduction}

The process of hospitalization is a very difficult and stressful experience for any individual, especially the children, due to the need to adapt to a new environmentand changes affecting their daily routine. Quality of physical and social hospital environment impacts the experiences of a child (Norton-Westwood, 2012). During their stay in hospital children scramble to find some connection with their living in the family, such as through nutrition, games and TV (Carney et al., 2003).

The impact of the disease on children and family life is already a very important issue. Numerous studies report that children experience feelings of anxiety, fear during their stay in hospital. Timmerman (1983) assessed fear in 16 children aged 10 to 12 years old who had undergone surgery for the first time. Their fears regarded loss of control pain or discomfort, injections, destruction of image of the body, separation from other important people. Fear of children about routine and unknown procedures, demonstrates the importance of preparatory procedures and programs for children (Ellerton and Merriam, 1994). Patient-centered services help in strengthening and improving self-management skills (Wagner et al., 2005). Other Studies support that such an approach can lead to an improved behaviour and health condition of the child (Dunst\& Trivette, 2009)

Parents of hospitalised children need mental-emotional support as well. Parents need help and instructions, in order to be able to help and care for their children (Callery, 1997). Family-centered care is also an essential element, which underlines the dynamic relationship between family members and treatment and health care offered by the medical team, as well as ways to involve family in the care (Corlett \& Tëycross, 2006). Parents' participation in the provision of care for children is viewed as a very essential element (Poëer \& Frank, 2008). Parents should be active participants in decisions taken in connection with child care provided. Parents have a dire need for information about the child's disease during their child's hospitalization. Information for parents must be on-going, and should reflect the 
development stages of the disease and include the new circumstances, taking into consideration parents' concerns. Information should be given in the form of a discussion dialogue so that parents are able to express what they think and ask questions in order to prevent any misunderstandings. This approach helps staff understand what are their fears and feelings, and provides time for questions they need to ask about the disease (Kliewer 1997).

\section{Methodology}

The mixed methods of data collection have been used to meet the objectives of the study. The review of literature as a first step also served for the preparation of instruments and created the basis for preparing the study framework. The use of quantitative methods aims at obtaining general information about perceptions of parents and hospital staff in general on services and support offered to children during their stay at the hospital. The use of quantitative methods helps in finding what is typical, average and representative of the population.

The qualitative methods of data collection have been used for a more profound analysis. Qualitative Methods can be described as an efficient model that happens in its natural environment and which enables the scholar get deeply involved in the current experience (Creswell, 2003). Qualitative Methods consisted in the collection of an as broader as possible information on experiences of parents during the child's hospitalization.

The sample included in this study represented a survey with parents $(\mathrm{N}=28) .10 \%$ of parents who had hospitalized children during the time of study were included in it. Parents included in the study had to fulfil the requirement of having hospitalized their children for a minimum of 3 days. Detailed interviews were carried out with 10 of the parents for a greater depth of information related to experiences during hospitalization. The study also included employees of hospital service, $10 \%$ of them were interviewed $(\mathrm{N}=25)$ in relation to the services provided to children and parents during the children's hospitalization.

\section{Results}

\subsection{First moments of hospitalization}

The presence, assistance, information and psycho-emotional support of the parent at the time before the child is hospitalized are very important. Considering interviews with parents and communication with social service specialists but also other observations conducted, it turns out that there is no hospital-provided procedure for the preliminary preparation of children and parents or their family members for the child's hospitalization and this fact is supported by $68 \%$ of the medical staff of Tirana paediatrics, who say that these procedures do not exist. Based on the interviews conducted directly with parents, it was noted that the most frequent emotions suffered by children before their hospitalization are: fear from hospital stay, fear of the unknown (they often ask: What have I got? What will happen with me when I go to the hospital, what will they do to me there?), feelings of anxiety, a state of apathy, sadness, boredom. Causes of these emotions, according to responses received, are as follows (Table 1):

Table 1: Causes of emotions in children before hospitalization.

\begin{tabular}{|l|c|c|}
\hline Causes of emotions before hospitalization. & Frequency & Percentage value. \\
\hline Failure to prepare for hospitalization & 6 & $21.4 \%$ \\
\hline Doctor & 1 & $3.6 \%$ \\
\hline Unknown hospital premises & 4 & $14.3 \%$ \\
\hline Surgical interventions & 3 & $10.7 \%$ \\
\hline Medical equipment & 13 & $46.4 \%$ \\
\hline Did not respond to the question & 1 & $3.6 \%$ \\
\hline Total & 28 & $100 . \%$ \\
\hline
\end{tabular}

According to the collected data, the mother is the parent who takes care of the child during hospitalization, in most cases, while the father cares for the rest of the family. Based on data from the questionnaires to parents and medical staff as well as observation conducted, the Tirana paediatric hospital does not offer any service to accommodate parents. They stay and sleep in the same room with the child. About $54 \%$ of parents say they are accommodated in the same bed with the child; while $32 \%$ of parents claim to be accommodated in a chair near the child's bed.

$92 \%$ of the parents receive information about the disease of their children from the specialist physician; this is very 
important to them, since it clarifies the situation and the child's problem thus increasing the security for the child's welfare. There is a lack of clarity and simplicity in providing information about the disease as doctors mainly explain based on their scientific language, which is not always easy to understand from parents. On the other hand, the child's information about the disease is very important, because it enables the child's understanding about his/her current physical conditions and explains why they feel pain in their body. $54 \%$ of the parents claim that children do not have information on their disease and only $46 \%$ of parents claim that children are informed about their disease. It is not easy for parents not to share information with their child about the disease, often thinking they are too young and can't understand, feeling confused in the explanation of the disease and believing that it's better that the child has no information about the disease.

\subsection{Experiences of parents and children during hospitalization}

Parents report some of children's experiences during hospitalization such as: physical pain as a consequence of the disease, physical fatigue, fear of pain caused by medical equipment, boredom, withdrawal in themselves and failure to express their feelings as before, desire to remember house objects, school friends, feelings of shame for the fact that they are sick, do not want the others to call them sick, can't wait to be released from hospital, desire to play with other children, continuous trauma due to serum injections, quarrel, etc.

Parents report that causes of their status are as follows (table 2):

Table 2: Causes of the psycho-social, physical and emotional status.

\begin{tabular}{|l|c|c|}
\hline Causes of emotions in children during hospitalization. & Frequency & Percentage value \\
\hline Doctor & 2 & $7.1 \%$ \\
\hline Hospital premises & 5 & $17.9 \%$ \\
\hline Surgical interventions & 2 & $7.1 \%$ \\
\hline Medical equipment & 12 & $42.9 \%$ \\
\hline All & 3 & $10.7 \%$ \\
\hline Adaptation with the hospital environment. & 3 & $10.7 \%$ \\
\hline Did not respond to the question & 1 & $3.6 \%$ \\
\hline Total & 28 & $100.0 \%$ \\
\hline
\end{tabular}

One of the social consequences suffered by hospitalised children is also their distancing from the daily routine, removal from their family, friends, relatives, distance from previously enjoyed activities, etc.

Parents and their children develop different activities which fill in time during their stay at the hospital. According to the data collected, 61 per cent of parents claim they talk to their children about topics that their children like; $29 \%$ claim that, with their children, they play games which do not harm their health; while $7 \%$ read books together with their child.

Some experiences reported by parents during the child's hospitalization time are: feeling worried about their current situation, experiencing fear for the future of the health of their child depending on the health problem, feeling anxious about the rest of the family especially for the young children they had to leave to the custody of family members or other, experiencing concern due to breaking away from work because of taking care about the ill child all the time, experiencing feelings of anxiety especially during long expectations to receive analyses' answers, some of them say they feel spiritual pain, several others say they have financial difficulties.

\subsection{The support provided by the staff of the hospital during the hospitalization time}

Referring to data from questionnaires developed with medical staff and observations conducted, children are more likely to request the help of medical staff to know when they will be released from hospital or when their pain will cease rather than to understand their disease. This is also linked to security offered by the doctor's image for the child and family members. According to data reported by doctors (table 3) 
Table 3: Children seeking help to understand their disease

\begin{tabular}{|l|c|c|}
\hline Do children seek help to understand their disease? & Frequency & Percentage value \\
\hline Always & 6 & $24.0 \%$ \\
\hline Sometimes & 13 & $52.0 \%$ \\
\hline Never & 6 & $24.0 \%$ \\
\hline Total & 25 & $100.0 \%$ \\
\hline
\end{tabular}

Medical staff report that only $16 \%$ of children are involved in the choice of the treatment form, the remaining $84 \%$ were not granted this opportunity. The questionnaires data analysis indicated that the reasons not to include children in the selection process of drugs or medications to be used were: the request of parents themselves not to involve children in such discussions, disease denial by parents is often seen as a way to protect children.

Observations conducted in the Tirana paediatric hospital indicated that hospital premises did not include any room for children entertainment. Moreover, some rooms which had been previously used as such have been turned into reception room for sick patients as a result of lack of premises for the hospitalization of sick patients. The psychological counselling room in some hospital wards served as entertainment room. The entertainment room in another hospital ward, once regularly used as such, was transformed into the psychological counselling and work office of the chief-nurse.

The psycho-social service is a new service provided only in recent years and there is still a lack of information on the importance of this service for children, parents and medical staff. Considering the conducted interviews $75 \%$ of parents confirm they are not aware that the paediatric hospital in Tirana offers a psycho-social service, meaning they do not have access to such services. Parents are mainly limited to receive medical services during their stay at the hospital, on the other hand, the employees of psycho-social service as well, being in their initial steps, have a difficult time to create their profile in relation to the needs of children and parents during their hospital stay.

\section{Conclusion}

Parents report that in general there is a lack of preparation procedures for the process of children hospitalization; in general parents are the ones providing greater support for their child. Lack of children's preparation for the hospitalization process causes anxiety, feelings of fear and uncertainty both to children and parents involved in the process of hospitalization. Inappropriate conditions for accommodation of children and parents during their hospital stay rendered difficult the staying of children and parents in the hospital. Along with coping with the physical disease, children did not have the necessary comfort for their stay and even parents demonstrated signs of fatigue as a result of the lack of conditions for their accommodation.

Most of the parents participating in this study have chosen not to inform their children about their disease and not to allow medical staff or even professionals of psycho-social service to do such a thing either. According to them this was a way to protect children from the information that would harm their well-being.

Medical staff focuses mainly on medical treatment of children during their stay at the hospital. They did not consider the psycho-social service as part of treatment for hospitalised children. Part of medical staff still cannot understand the importance the psycho-social service both for the child and for them as professionals as they would be able to fully conduct medical services and increase the quality of satisfaction and welfare received by children and parents during their stay at the hospital. The psycho-social service was included as a service of the paediatric hospital from a few years and was not functional for sick children and their families. Their focus remained in the context of children's treatment during their stay at the hospital, and only for those who in a way or another had information about the existence of this service and were aware of the positive aspects brought by this service in the medical treatment of hospitalised children. 